\title{
Brasilio Machado e a Academia (*)
}

\section{Ernesto Leme}

$O$ ano de 1868 foi dos mais auspiciosos na vida da Academia. Aqui aportavam, vindos do Recife e precedidos de grande fama, os estudantes do terceiro ano Ruy Barbosa e Castro Alves, que passaram a refulgir, como estrelas de primeira grandeza, na turma de Rodrigues Alves, Affonso Penna e Joaquim Nabuco. E, entre os quarenta e sete rapazes, que se matricularam no primeiro ano, estavam os nomes gloriosos de João Monteiro e Brasilio Augusto Machado de Oliveira.

Viéra este das aulas do Seminario Episcopal, que o venerando d. Antonio Joaquim de Melo creára, em 1859. Concluira os preparatorios no Curso Anexo. E, aos dezenove anos e meio, quase na idade com que, vinte e sete anos mais tarde, seu filho Alcantara Machado aqui conquistava a laurea de professor, iniciava Brasilio a sua trajetória, nesta Faculdade.

Bacharel em ciencias jurídicas e sociais, em 1872, promotor público de Piracicaba e Casa Branca, inspetor do Tesouro, secretário da Relação, já doutor em direito, desde 1875, vem disputar nesta Casa, em 1882, o cargo de lente substituto.

Dos cinco concursos, que então se abriram, inscreveuse em tres - nas vagas de Joaquim Augusto de Camargo,

(*) Discurso proferido a 4 de setembro de 1948, na Faculdade de Direito, por ocasião do centenário do nascimento de Brasilio Machado. 
Leite Moraes e Rubino de Oliveira, nomeados lentes catedráticos. Seus competidores eram da estatura de João Mendes Junior, Dino Bueno, Brasilio dos Santos, 'Teófilo Dias, Leite Moraes Junior, Joaquim Manuel Carlos de Gusmão, Lopes dos Anjos. Em todos êles logrou aprovação e indicação. Nomeado lente substituto, na vaga de Leite Moraes, por decreto de 30 de junho de 1883, do governo Imperial, tomou posse a 7 de julho.

Promovido a catedrático de direito natural, a 30 de setembro de 1890, passou, mêses após, com o desdobramento da cadeira de direito comercial, a reger esta disciplina, da qual apenas se afastou definitivamente com a sua morte, ocorrida a 5 de março de 1919.

$O$ ensino do direito mercantil iniciára-se nesta Faculdade com Clemente Falcão, nomeado lente em 1830. Doutorára-se êle em direito na Faculdade de Paris. E arrepelava a sociedade paulistana da época, com o seu odio doentio aos padres e às mulheres.

Aqui permaneceu por trinta e quatro anos, substituido na cátedra, em 1864, por Antonio Carlos Ribeiro de Andrada Machado e Silva, talento peregrino a que não correspondia, contudo, uma grande dedicação às letras jurídicas.

Já em Congregação de $1 .^{\circ}$ de março de 1882 , ao se discutir o parecer sobre o projeto de fundação de uma Universidade na Côrte, reclamava Antonio Carlos se instituisse mais uma cadeira de direito comercial, afim de ser o ensino da materia realizado em dois anos consecutivos. Impugnou sua proposta Vieira de Carvalho, por se haver reservado tres anos ao estudo do direito civil, não sendo o comercial, como entendia, senão um desdobramento daquêle. Só a reforma Benjamin Constant possibilitou a creação da nova cadeira, confiada a Brasilio Machado. Passou êle a dividir a responsabilidade de ensino da disciplina com o lente catedrático, Brasilio Rodrigues dos Santos.

Teria razão Alcantara Machado em dizer que seu pai foi quem, por assim dizer, "inaugurou o ensino do direito 
mercantil na Faculdade de São Paulo", se Brasilio dos Santos, seu concorrente em dois concursos, não o houvesse precedido, embora de alguns mêses, na regencia de igual cadeira. Sem o brilho e a sedução pessoal de Brasilio Machado, que exercia, entre os mestres, o primado da oratoria acadêmica, era o filho de Gabriel Rodrigues dos Santos, na frase do proprio Alcantara, "homem de carranca fechada e sólida cultura." As suas preleções taquigrafadas demonstram o seu preparo e o seu devotamento à cátedra que exercia. E o Esboço de Constituiçâo Federal, publicado em 1890, "formulado sob a inspiração de doutrinas professadas durante alguns anos de magisterio", revela o seu zelo de patriota e a sua familiaridade com os problemas do direito público.

Quando iniciei os meus estudos nesta Faculdade, em 1915, estava Brasilio Machado afastado de sua cadeira havia quatro anos, desempenhando as funções de presidente do Conselho Superior de Ensino. Fôra eleito pela Congregação, mêses antes, para o cargo de diretor, no bienio 19151916. Recusára esse posto, em virtude das funções, que então exercia, manifestando, em carta a João Mendes Junior, o imenso pezar em se conservar arredado do convivio de seus colegas de São Paulo. Não pude receber, assim, diretamente, suas lições, nem ter a fortuna de ouví-lo. Nem de vê-lo.

Do esplendor de suas aulas fala a unanimidade de seus discípulos. Pelagio Lobo refere as que êle professou, em 1908, sobre direito marítimo, convertendo a explanação de temas áridos em puras obras de arte e transformando a materia "num torneio verbal de inesquecivel encantamento" Reynaldo Porchat assinala o "fundo sulco luminoso traçado pela argumentação encantadora e pela eloquencia deliciosa de Brasilio Machado", na cadeira de direito comercial. E ainda esta manhã, numa carinhosa evocação de mestre, rememorava a sua cintilante lição sobre a comercialidade dos imoveis, que o erroneo entendimento de um texto de Ulpiano, no Digesto, Livro L, tit. XVI, de ver- 
borum significatione, 66, levou o comum das legislações a excluir do campo do direito mercantil.

Para se aquilatar do valor de Brasilio, como professor, basta ler, quarenta anos decorridos, com as imperfeições da taquigrafia, as preleções não revistas que dêle se encontram. Nada de essencial na materia era esquecido. A exposição, de clareza transparente. Perfeito o encadeamento do assunto. A frase, sempre límpida e cantante.

Haja vista as que proferiu sobre ato de comercio, por êle conceituado como "uma função orgânica de mediação especulativa entre a oferta e a procura das mercadorias, preordenada à circulação econômica". Constitue êsse, como destaca, um "problema insoluvel para a doutrina; um tormento para o legislador; um enigma para a jurisprudencia". Porque, em verdade, nêle se encerra todo o conteudo do direito mercantil.

Reconhecendo a estreita afinidade entre o direito comercial e o civil, - "porque um e outro, se bem que em relações diversas, submetem o mesmo objeto, o mesmo sujeito de direito", - inscreve-se, com Cesare Vivante, entre os propugnadores da unificação do direito privado.

Antes de Endemann e do mestre italiano, a idéa surgira no Brasil, com Teixeira de Freitas, na proposta para a elaboração de um Código Geral, endereçada ao governo, em 1867: "Não ha tipo para essa arbitraria separação de leis, a que deu-se o nome de direito comercial ou Código Comercial; pois que todos os atos da vida jurídica, excetuados os benéficos, pódem ser comerciais ou não comerciais, isto é, tanto pódem ter por fim o lucro pecuniario, como outra satisfação da existencia". O governo, porém, repeliu o alvitre, pelo aviso de 18 de novembro de 1872 .

Viveu Brasilio Machado o suficiente, para ver sua aspiração, por êle pregada convictamente, sobretudo na lição inaugural de 1897, renascer, em 1911, no projeto Inglês de Souza. Mas, não alcançou a conversão de Vivante à corrente favoravel à dicotomia do direito privado e menos 
ainda a idéa do Código Geral, triunfante na legislação italiana, em 1942.

Alcantara Machado nos revela, na biografia de Brasilio, em fac simile, um dos esquemas organizados pelo pai, na preparação de suas aulas. "Custavam-lhe horas e horas de meditação e de estudo os quarenta e cinco minutos da preleção". De Cújacio se dizia que esse trabalho consumia dez horas. .

Inteiramente em dia com a sua disciplina, coisa alguma de quanto a respeito se publicava, aqui ou no estrangeiro, escapava à percepção de Brasilio Machado. Esse o segredo de seu triunfo. E porque as palavras lhe brotavam aos borbotões, como a agua cristalina que jorra da fonte Inesgotavel. As lições incomparaveis não eram apenas fruto de sua dialética de advogado, ou de sua fluencia de orador; provinham, sobretudo, da sedimentação de sua cultura jurídica.

O mestre era tambem um artista. Consideravam-se as suas arguições em concurso, apavorantes; apavorantes, está visto, para os candidatos. . Maneiroso, suave, de polidez impecavel, estringia o concorrente nos aneis de ferro de sua lógica, até prostrá-lo, exânime, sem força de reação. Dizem-no quantos o escutaram e admiraram.

Seu poder de persuasão era simplesmente formidavel. Eis a causa de suas magníficas vitórias no fôro, sobretudo no fôro criminal. Nesta especialidade, era considerado o maior advogado brasileiro de seu tempo. E notavel é que o fosse um professor de direito mercantil... Como o destino reservava a Gama Cerqueira, grande professor de direito penal, ser um dos príncipes da advocacia civel, em São Paulo...

O poeta das Madressilvas e Perpetuas ainda cultivava as musas, nos albôres da velhice. Mas, poeta, prosador, advogado, mestre de direito, jornalista, a sua gloria mais pura êle a obteve, em verdade, como orador. "Mágico da eloquencia", chama-lhe, com justeza, Reynaldo Porchat. 
Alude o mestre de direito romano aos dois famosos oradores, com que contava a Congregação de seu tempo: João Monteiro e Brasilio Machado. Colegas de turma, enIraram para o corpo docente na mesma época. Alteavam-se ambos, como gigantes da mesma estatura.

João Monteiro era o mestre da palavra. "Podia deixar a frase manca, sem arredondá-la em harmonia. Mas a palavra, sempre escolhida e lídima, êle tinha o capricho de pronunciá-la com a máxima correção". Brasilio era o mestre da frase. "Podia não caprichar na dicção de uma palavra, contanto que se não perturbasse o rítmo de uma frase pronunciada com harmonia e sonoridade"

Conhecemos tambem na Faculdade, em meu tempo de estudante, dois notaveis oradores: Herculano de Freitas e Reynaldo Porchat. A sobriedade dos discursos do primeiro desde logo nêle evidenciavam o orador parlamentar, por excelencia; o colorido da frase, a opulencia do vocabulario, o fulgor das imagens, destacavam no segundo o artista insuperavel da oratoria acadêmica. Poderia ser colocado, entre João Monteiro e Brasilio Machado, como o mestre da frase e da palavra. Seus períodos eram sempre sonóros e cantantes; mas, os vocabulos, escandidos, na perfeição de seu enunciado, formavam um colar de pérolas, em que nenhuma desmerecia das outras, na pureza de seu oriente.

Antonio de Alcantara Machado, promissora inteligencia, em quem a vocação literaria do pai e do avô revivia, no eterno enamorado da Beleza, dizia nesta mesma tribuna, precisamente ha vinte anos, dos "períodos balançados de orador romântico", do verbo de Brasilio. Quem se detém, contudo, seduzido pela caricia dos trópos incomparaveis de sua saudação a Carlos Gomes, sente-se tentado a nêle vislumbrar a eloquencia condoreira, cujos arroubos nos evocam a poesia de Castro Alves, seu amigo e companheiro e a quem assistiu, desveladamente, ao lado do padre Chico de Paula, em seus tormentosos e derradeiros dias de São Paulo. 
Os que hoje Iêem os inimitaveis discursos de Brasilio e tiveram, também, a graça divina de ouví-lo, enaltecem 0 valor da palavra, que se eterniza, mas, proclamam que the falta a ela a sonoridade do instrumento, que lhe transmitia o milagre da sua musicalidade. "A escrita", falava Manuel Carlos, "sugere a idéia representada. Apesar de inerte, é um símbolo que póde eternizar o pensamento, na sua plenitude. Mas a imagem do verbo articulado, da palavra viva, essa, nenhum artificio conseguiu até hoje fixar".

Eis o que nos falta, nos discursos de Brasilio. A figura senhoril do orador, a fronte larga, a cabeleira ondeante, os olhos vivos e penetrantes, dominando o auditório magnetizado. E a sua voz tinha todas as modulações, óra suave, como o veludo, óra cortante, como um látego. Sóbrio nos gestos, suas mãos fidalgas acompanhavam o sentido da expressão, dando-lhe maior força e vigor. óra tremiam, nervosas, nos arroubos tribunicios, óra se estendiam, blandiciosas, como numa bênção.

Ouvindo-o, não havia quem descresse do milagre do verbo. "Foi para o fio da espada que se fez o fio da palavra", dizia êle em sua conferencia, no tricentenario de Anchieta. "O rugido das féras no Coliseu não pôde abafar a confissão dos mártires, - que ao baraço que intima o silencio, o apostolado cristão jamais se descuidou de opôr a caridade que intima a pregação".

Vêde-o agora, orando na solenidade do 11 de Agosto, em uma época de incertezas e temores: "Não é raro nos horizontes africanos, aparecer o sol, como um disco sem raios, um corpo sem fulgurações: - é que o vento bateu asas sobre o dorso dos desertos, e a areia sacudida enchendo o espaço parece quebrar em lâminas sutís e sanguinolentas a luz do astro poderoso. Erguer, neste período de ansiedades públicas, a data de hoje acima dos horizontes de nossa vida social, é como que refletir a imagem do sol africano, - um disco sem raios, um corpo sem fulgurações; - e cada um de nós poderia ver, no pó que, a patas de corcel, o gaúcho rio-grandense sacóde das campinas do sul, essa 
mesma areia do deserto que transfórma a luz em poeira de sangue, e o céu num braseiro de cinzas requeimadas".

Enlevai-vos tambem neste milagre de síntese, em que Brasilio condensa, num período, toda a epopéia de um povo, no ciclo mais glorioso de sua existencia: "Portugal, essa nação pequenina que a Espanha comprime, mas que o oceano alarga; essa nova Grecia dos argonautas da gloria; esse mesquinho átomo de terra que na história ganhou as proporções sobranceiras de uma montanha; Portugal, em face das ondas, em cujos términos só póde a mão do genio rasgar as sombras do desconhecido, sentia delinear-se, abrir, crescer a róta luminosa de seus descobrimentos que longe levaria a fama do seu nome, o nome de seus heróis, os heróis de sua imortalidade, a imortalidade de seu patriotismo".

Eis porque era Brasilio Machado, na frase lapidar de Baptista Pereira, desses oradores "que fazem da palavra a substancia mesma da Vida e da Beleza".

Em maio de 1911, assumindo, na Capital Federal, as altas funções de presidente do Conselho Superior de Ensino, creado pela refórma Rivadavia, afastou-se o mestre de sua cátedra. Os derradeiros anos de sua existencia foram, ainda assim, consumidos ao serviço da instrução. Fez-lhe justiça o seu sucessor na presidencia do Conselho, doutor Ortiz Monteiro, ao assinalar: "A rajada de anarquia, de confusão demolidora do ensino federal, gerada pela Lei Orgânica do Ensino completando a obra de destruição sistemática do sábio Codigo do Ensino de 1901, fez com que melhor se evidenciassem os predicados de cultura e de bom senso, que caracterizaram a ação administrativa do primeiro presidente deste Conselho".

Mas, a vida do nobre lidador chegava ao seu termo. Advogado e publicista, lente de direito e administrador, acupára, em sua existencia, as mais elevadas posições. Candidato a deputado, não lhe sorriu a sórte, nas urnas. Coube-lhe, porém, por nomeação do governo Imperial, a presidencia da provincia do Paraná. 
Católico praticante, êle tinha, na bagagem de suas obras pias, a propria conversão do pai. Foi um legionario do direito e um estrênuo defensor da fé. Por isso, agraciado por sua santidade o papa Leão XIII, com a cruz Pro Ecclesia et Pontifice, galardoou-o Pio $\mathrm{X}$ com o título de barão da Santa Sé.

Amando extremadamente à sua terra, quís morrer em São Paulo. Cantavam em seus ouvidos os versos que escrevera, nas Madressilvas:

Vinde, filhos de além, ver quanto é doce sob a curva do céu aqui sonhar...

Viveria das suas reminiscencias. Como Cipião, o Emiliano, poderia evocar as sombras amigas, para assistí-lo no transe derradeiro - desde Antonio de Oliveira, companheiro de Martim Afonso, até José Joaquim Machado de Oliveira, que êle reconduzira à compreensão do Senhor. "Justitiam cole", todos lhe diriam, e êle sempre cultivara a justiça; recomendar-lhe-iam servisse a patria, antes de tudo, — "tum in patria maxima est", - e êle consagrára a sua existencia à educação da juventude, que é sempre a esperança da nacionalidade.

Conta Antonio de Alcantara Machado que uma tarde, do terraço de sua casa, em Higienópolis, divisou Brasilio o perfil do Jaraguá, que se alteava sobranceiro à distancia, sentinela avançada velando pela tranquilidade do burgo paulistano. E, como nas asas de um sonho, acudiram-lhe a memoria os versos de sua juventude:

É este o meu patrio monte que junto ao rio cresceu...

E o monte poderia contar-lhe a história de sua terra e de seus ávitos. Um dia, os guaianás, que habitavam o planalto, assistiram à chegada de gente estranha, que aí vinha estabelecer uma escola e edificar uma capela. Ajudaram os indios bater os muros de taipa e ofereceram aos recemvindos os recursos primitivos de que dispunham. Os filhos de 
Bartíra e de João Ramalho foram os primeiros discípulos do colegio de Anchieta.

Dois séculos e meio mais tarde, da estirpe de Antonio de Oliveira, nascia um varão, José Joaquim Machado de Oliveira, a quem Afranio Peixoto apelidou "bandeirante retardado, heroico e ilustrado" e de quem Joaquim Manuel de Macedo dizia que "a amplidão do seu peito mal chegava para as condecorações que atestavam o seu merecimento." Mas, a gloria de Machado de Oliveira, guerreiro, politico e historiador, chega mesmo a empalidecer, ante o orgulho de se sentir reviver na gloria de Brasilio.

Juntos dormem, agora, o eterno sono. Foram a êles juntar-se dona Maria Leopoldina, a Musa que inspirára ao poeta os seus mais doces carmes, Alcantara Machado e Antonio de Alcantara Machado.

Sobre a pedra que então cobria os despójos do pai e do avô, fez Alcantara Machado esculpir, pelo genio de Brizzolara, uma esplêndida apoteóse, representando a corrida de archotes, de Lucrecio. Quando aquele que empunha a flama sagrada tomba exânime, um éfebo toma o brandão, resoluto e, olhos postos no futuro, prossegue na caminhada. A luz que se apagou, na vida de Machado de Oliveira, reacendeu-se de novo nos olhos de Brasilio...

O tempo se incumbiu de tornar mais perfeito o simbolismo. Nada menos de quatro gerações nessa tumba agora se representam e todas elas se assinalando por obras meritórias.

Na data centenaria de Brasilio, reverenciemos os mortos que repoisam nesse túmulo. Porque nêle se recolhe um trecho vivo da Historia. 